\title{
Investigating the feasibility of co-production of digital media with students
}

\author{
Karin Johnstone \\ University of Northampton, UK
}

\section{Samantha Thomas}

University of Northampton, UK

\section{Nathan Dodzo}

University of Northampton, UK

\begin{abstract}
The Learning Development (LD) team has a suite of online videos which aim to provide students with support and guidance in a range of academic skills. The usage statistics show that they are more widely used than other content such as PDF documents or visual guides. An audit of these videos revealed that most were written by or featured academic and professional staff, were of poor technical quality, and were 'talking heads' which, rather than encourage active learning, may result in passive engagement and therefore shallow rather than deep learning (Ryan, 2013). An opportunity was identified to remake videos in collaboration with students to address these issues and to increase student participation and representation in learning development content. Two LD tutors and a media and journalism lecturer collaborated on a project to co-produce academic skills videos with students. Students were given a brief to create videos based on their own experience of study skills. They also took part in focus groups and completed a survey to find out more about their perception of educational videos and the experience of creating their own. There were two main aims in undertaking the project: the creation of original content by students that addressed some of the concerns we had about the efficacy of existing videos, and the development of a model of co-production which could be used as a framework to produce future content in collaboration with students.
\end{abstract}

Keywords: video co-production; active blended learning; educational videos; student created videos; life brief; service learning. 


\section{Introduction}

This project aimed to develop greater knowledge and understanding of what features of educational videos contributed to student learning, and, as a result, to be able to provide resources in line with these findings. An additional consideration was that we would be able to provide a real-life professional brief for students to work to, which would provide an authentic assessment opportunity (Frey et al., 2012), contribute to their portfolio of work, and thereby enhance their future employability.

Research has already established the growing importance of video as an educational tool. Student feedback on their preferences has been analysed and put into practice; for example, videos must provide 'something extra' to other resources, and the presentation of visual examples is an important element (Rice and Farmer, 2016). Researchers have also explored the variety of tools used to produce videos (Baker, 2016) and developed guidelines for producing effective videos based on pedagogical models and research (Brame, 2015). These studies provide a solid foundation for us to develop questions and focus on specific aspects of the production process with our student cohort.

We built on this research by gathering qualitative feedback from students via focus groups on what, for them, makes an effective educational video. Using this research as a starting point, new video content was created with the students as co-producers. Finally, a core set of principles and guidance for producing video content in line with student recommendations and preferences are being developed, which can be used by any subject area.

The university has an open access online skills portal where students can find guidance about a variety of academic skills. Institutional research showed that students access the video content on this site more than any other resource type including the print PDF documents. The 12 most popular academic skills resources were videos. However, a review of this online video content established there were many issues: the technical quality of the video and audio was poor, the majority were too long, and the audio narration was not engaging. Mayer's multimedia voice principle (2017) states that a human voice, not a machine voice, should be used in presentations. Although the voice- 
overs were not machine-generated, some sounded monotonous and machine-like, and were not as engaging as they could be.

Hampe found that videos with a 'talking head' presenter can turn the viewer into a 'zombie', in other words a passive learner (1999, cited in Majekodunmi and Murnaghan, 2012, p.3). As a team we aim to create more active online learning for students, and to include more student feedback and participation in the creation of resources. As a result, we decided that video content should be remade and updated, using it as an opportunity to involve students as co-creators of the new video content.

\section{The Project Process}

The project had six stages:

1. Researchers met with students to introduce the project and obtain consent for participation.

2. Student focus groups were conducted to explore what makes educational videos effective.

3. Students were given the project brief to create the videos within a given timescale.

4. Students pitched initial ideas for their videos to the researchers - feedback was given, and videos commissioned.

5. Students created their academic skills videos and presented these to the project researchers/clients.

6. A follow-up survey was sent to all student participants to explore their experiences of taking part.

A first-year cohort of 26 media students who were taking the module 'Digital and Social Media Production' were chosen for the project. Focus group participants were volunteers from the cohort; two small groups of students viewed a selection of academic skills videos, then took part in discussions assessing the effectiveness of these resources before they went on to produce videos of their own. Ethical approval for the study was granted by the university, and participants were fully informed about the 
research process before they gave their consent to take part. They were able to withdraw from the research project at any time.

As part of the module assessment, students had to produce several videos for their portfolio; creating an academic skills video could successfully be embedded into this structure. Reflecting professional media practices, and in line with the module criteria and learning outcomes, the LD tutors acted as 'clients' and presented a professional 'client brief' to the students. Students were encouraged to look at the video content on the university skills portal and to research other academic skills videos in order to choose a theme or skill, and then pitch their ideas to the researcher 'clients'. Feedback from the 'clients' enabled students to refine and focus their plans, which were then produced as draft videos.

\section{Focus groups}

Two focus groups took place, of four and five students respectively. Each group watched five academic skills videos that are produced by and hosted on the skills support websites of five different HE institutions, each of which demonstrated a different style or approach. Student comments about the videos made during the focus groups are summarised in Table 1. 
Table 1: Focus group comments on educational videos

\begin{tabular}{|c|c|c|c|c|}
\hline Video content & Producer & $\begin{array}{l}\text { Duration } \\
\text { (mins.secs) }\end{array}$ & Focus Group 1 comments & Focus Group 2 comments \\
\hline $\begin{array}{l}\text { Students giving tips } \\
\text { about reading } \\
\text { strategically }\end{array}$ & $\begin{array}{l}\text { Learning } \\
\text { Services in- } \\
\text { house }\end{array}$ & 2.42 & $\begin{array}{l}\text { Student interviews mean 'you feel more } \\
\text { comfortable, rather than hearing from an } \\
\text { older voice'; range of students therefore } \\
\text { something for all; 'the audio was really bad' }\end{array}$ & $\begin{array}{l}\text { Good layout; quick, short points - 'it definitely } \\
\text { keeps your interest'; 'having different opinions } \\
\text { is good'; noise quality changed a lot }\end{array}$ \\
\hline $\begin{array}{l}\text { Light-hearted } \\
\text { animation about } \\
\text { evaluating information }\end{array}$ & $\begin{array}{l}\text { Commissioned - } \\
\text { professional } \\
\text { production }\end{array}$ & 1.23 & $\begin{array}{l}\text { Pacing 'perfect'; high-quality, professional } \\
\text { animation; humorous with visual gags; easy } \\
\text { to follow; too general in content }\end{array}$ & $\begin{array}{l}\text { 'Grabbed my attention right from the start'; 'at } \\
\text { points it seemed a little bit patronising'; } \\
\text { animation 'completely unrelated to what's } \\
\text { actually being said' }\end{array}$ \\
\hline $\begin{array}{l}\text { Videoscribe about } \\
\text { critical writing }\end{array}$ & $\begin{array}{l}\text { Learning } \\
\text { Services in- } \\
\text { house }\end{array}$ & 7.47 & $\begin{array}{l}\text { 'It was really interesting, but it just felt too } \\
\text { long'; too many pauses, too slow; '[it] felt } \\
\text { like a lecture and that's not the kind of thing } \\
\text { I want to hear' }\end{array}$ & $\begin{array}{l}\text { 'You couldn't stay engaged after three } \\
\text { minutes'; 'way too much information'; 'bad } \\
\text { audio levelling'; 'needs a bit more emotion with } \\
\text { the voice' }\end{array}$ \\
\hline $\begin{array}{l}\text { Video with student } \\
\text { presenters about } \\
\text { group work }\end{array}$ & $\begin{array}{l}\text { Student } \\
\text { produced }\end{array}$ & 4.01 & $\begin{array}{l}\text { 'This felt like advice to me from students } \\
\text { who were also doing the same thing, so it } \\
\text { felt nicer to listen to'; 'this is a group of } \\
\text { friends and they were fun to listen to' }\end{array}$ & $\begin{array}{l}\text { 'I like how they related it to themselves'; 'learn } \\
\text { from our mistakes'; audio levels 'terrible' }\end{array}$ \\
\hline $\begin{array}{l}\text { Montage with images } \\
\text { and text about } \\
\text { choosing sources }\end{array}$ & $\begin{array}{l}\text { University in- } \\
\text { house }\end{array}$ & 1.27 & $\begin{array}{l}\text { Felt rushed; video quality not great; seemed } \\
\text { old-fashioned; music too loud }\end{array}$ & $\begin{array}{l}\text { 'the whole thing was just flashy animations'; } \\
\text { 'the upbeat music helps you engage a lot } \\
\text { more' }\end{array}$ \\
\hline
\end{tabular}




\section{Analysis of focus groups}

We were surprised at the degree to which opinions varied regarding the strengths and weaknesses of the videos, and this is perhaps due to the mix of personalities and impact of group dynamics, which have been identified as a limitation of using focus groups (Stewart et al., 2007). Overall, the participants responded positively to student participation in the videos and welcomed the opportunity to learn from others in a similar situation to themselves. Both groups disliked the lecture style video; however, the main drawbacks identified in all videos tended to be technical, for example that some were too long, or the audio was of a poor quality. There was no consensus on style, pace, and use of music or animation.

\section{Project briefs and video production}

Students had three weeks between receiving the initial brief and the meetings in which they needed to present their pitches, and then 12 weeks to produce the first drafts of their videos (which included the Christmas break). Of the eight groups that presented pitches, four videos reached the final draft stage and are now resources hosted on our skills website. The final videos focus on time management, assignment planning and notetaking skills, and present refreshing, dynamic and engaging student views of these topics. They all focus on the student experience by using student 'actors' (the students working on the videos and their friends, some of whom were studying acting) who address the viewer directly to give advice or guidance. They all incorporate humorous aspects, for example by using music, props, editing techniques and storylines to highlight common mistakes or to make a point. The finished videos ranged in length from 3.23 to 6.22 minutes, and most kept to the brief of producing a short video on a specific study skill. We are thrilled with the resulting videos, which add significantly to the diversity of approach and overall appeal of our existing resources, and which have so far received positive feedback from colleagues. In the near future we will evaluate the effectiveness of these videos as learning tools for other students. 


\section{Student feedback}

An online survey exploring the students' views of the project and aiming to identify any additional benefits of taking part was distributed to all students in the cohort at the end of the project. 15 students responded, including all the students that took part in the focus groups, and all agreed that taking part in the group activity positively influenced their approach to developing their video. Their reasons for choosing the topics of their videos varied, but most based the decision on what they thought would be useful. They were also asked to rate their perception of the improvement in their knowledge of the skills explored in the video and their technical skills in video production (Figures 1a and 1b). Most students thought that their skills had improved in both areas, interestingly, more in skills development than in technical skills. Those that had taken part in the focus groups were more likely to report an increase in their knowledge of the academic skill on which they had worked. It could be argued that the focus group activity, in which the content of videos was discussed, enabled students to focus on the purpose of the videos. This in turn meant that when they came to develop their own videos, greater emphasis was placed on the academic skills content for these students, and they therefore learned more about the skill area on which their video was based.

Figure 1a. Student self-evaluation of skill improvement after taking part in the project: focus group participants.

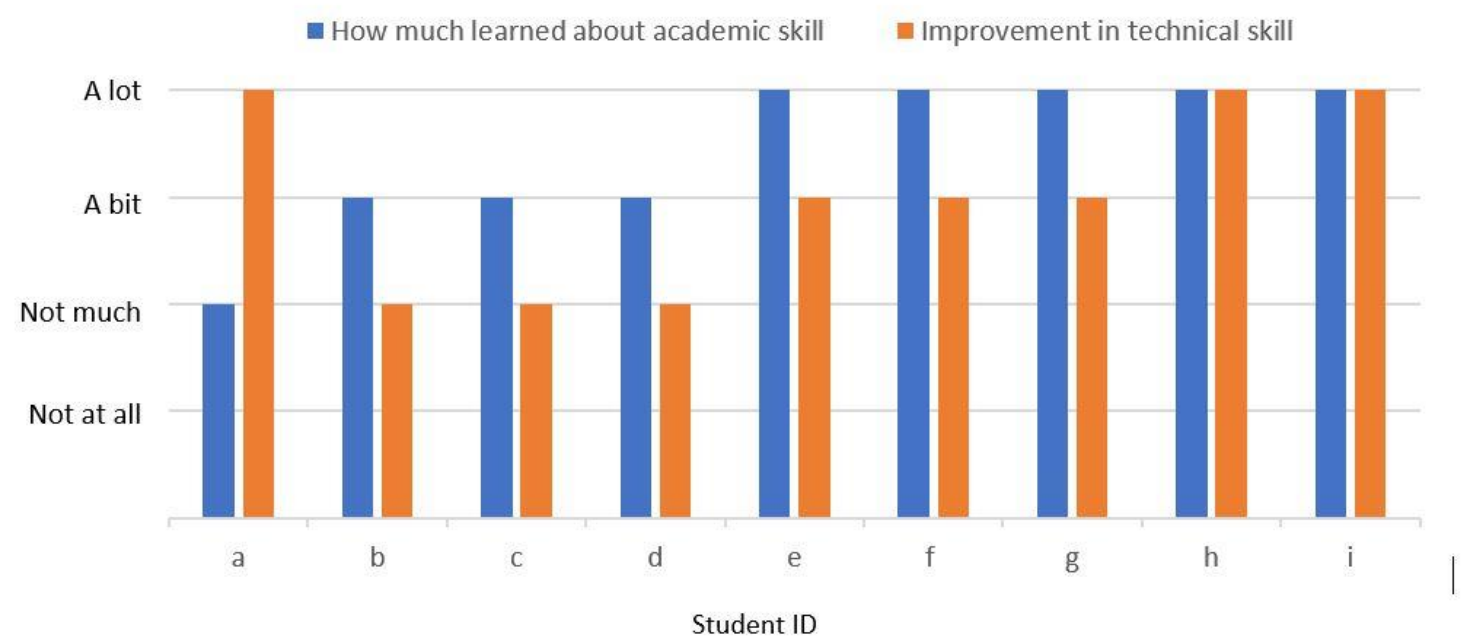


Figure 1b. Student self-evaluation of skill improvement after taking part in the project: other students.

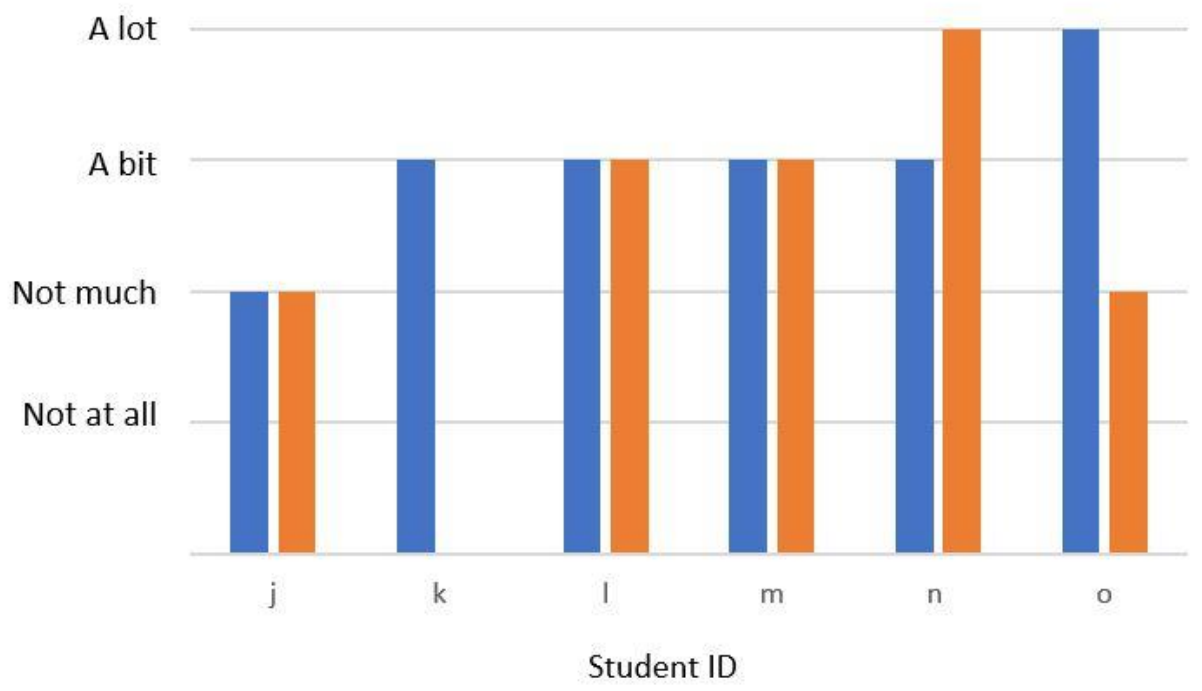

\section{Discussion and reflection}

There were many benefits to this project. It was clear that this process gave students autonomy in the creation of their own academic skills videos, which gave them a voice and meant that they could see themselves represented in university resources. An additional benefit was that they actively learned about both video production and the skills they were presenting in the videos. The project involved collaboration between academic staff, students and learning development tutors, which could potentially break down barriers for students wanting to use LD services in the future. The project also embedded academic skills into the module in a creative way; students learned about specific academic skills in the process of making videos for clients.

We found the process of working with the students to produce the videos enlightening and enjoyed their refreshing perspectives and enthusiasm, so we would recommend this approach to developing video content. The main recommendations from this project would be:

- Allow adequate time for planning, briefing and giving feedback to students to ensure they keep to the brief and complete the project. 
- Encourage students to do plenty of research on the topic of the video and provide specific support to ensure the content is accurate. One group produced a video about referencing that reached the draft stage with incorrect references and was therefore not completed.

- Think carefully about how to employ or engage with students. We chose this cohort because making videos was a core component of their module, and the project could be classified as an authentic assessment in this context. However, to facilitate this in other subject areas would require a different approach to assessment or involve engaging students outside of their formal studies, in which case additional incentives may be required.

- Producing professional quality videos was not our aim and would probably be unachievable for a project like this. We were impressed by the technical competence of the students; however, the resulting videos were imperfect, and we accepted early on that the videos would be variable in quality.

- Ensure that students have planned for all eventualities. Despite their specialist knowledge, students still had issues in sourcing actors and gaining permission for filming, meaning that there were last-minute changes to scripts and plans.

\section{Next steps}

We are currently evaluating the impact of the videos on students and how well they are received in comparison to our existing resources, using the criteria generated by the students in our focus groups. We are also using this experience to fully develop a set of guidance and principles for creating videos with students for our own use and potentially others across the whole university. In future we would like to repeat a similar project with non-media students and academics. 


\section{References}

Baker, A. (2016) 'Active Learning with Interactive Videos: Creating Student-Guided Learning Materials', Journal of Library \& Information Services in Distance Learning, 10(34), pp.79-87. Available at: https://doi.org/10.1080/1533290X.2016.1206776 (Accessed: 22 November 2018).

Brame, C. J. (2015) 'Effective educational videos', Vanderbilt University Center for Teaching. Available at: http://cft.vanderbilt.edu/guides-sub-pages/effectiveeducational-videos/ (Accessed: 22 November 2018).

Frey, B. B., Schmitt, V. L. and Allen, J. P. (2012) 'Defining authentic classroom assessment', Practical Assessment, Research and Evaluation, 17(2). Available at: https://pareonline.net/pdf/v17n2.pdf (Accessed: 22 May 2019).

Majekodunmi, N. and Murnaghan, K. (2012) "'In Our Own Words": Creating Videos as Teaching and Learning Tools', Partnership: the Canadian Journal of Library and Information Practice and Research, 7(2), pp.1-12. Available at: https://journal.lib.uoguelph.ca/index.php/peri/article/view/2007 (Accessed: 29 May 2019).

Mayer, R. E. (2017) 'Using multimedia for e-learning', Journal of Computer Assisted Learning, 33(5), pp.403-423. Available at: https://doi.org/10.1111/jcal.12197 (Accessed: 29 May 2019).

Rice, P. and Farmer, R. (2016) 'Educational videos - tell me what you want, what you really, really want', Journal of Learning Development in Higher Education, 10. Available at: http://journal.aldinhe.ac.uk/index.php/jldhe/article/view/297 (Accessed: 22 November 2018).

Ryan, B. (2013) 'A Walk down the red carpet: Students as producers of digital video-based knowledge', International Journal of Technology Enhanced Learning, 5(1), pp.2441. Available at: https://doi.org/10.1504/IJTEL.2013.055950 (Accessed: 16 October 2019). 
Stewart, D. W., Shamdasani, P. N. and Rook, D. W. (2007) Applied Social Research Methods: Focus groups. $2^{\text {nd }}$ edn. Thousand Oaks, CA: SAGE Publications, Ltd.

\section{Author details}

Sam Thomas is a learning development tutor at the University of Northampton. Prior to this she worked in academic and public libraries in a range of professional roles, including reader development, teaching digital literacy, and supporting a wide range of library users. Her current research interests include the role of language in teaching and learning, and how best to support top-up students in business subjects in reaching their full potential.

Karin Johnstone is a learning development tutor at the University of Northampton. Prior to this position she led an HND in film making and was previously head of screen writing at the South African School of Motion Picture and Live Performance in Cape Town. Johnstone also worked as an engineer at Channel 4 television. Her interest in film making and storytelling is evident in her academic research in using video and narrative based projects with HE students.

Nathan Dodzo is a senior lecturer in media and journalism at the University of Northampton. He is also the programme leader for the Creative Film, Television and Digital Media Production programme. He is a passionate, enthusiastic, energetic, selfmotivated educator with extensive high-level teaching, broadcast and journalism experience, and the ability and skills to translate these into effective and meaningful learning. He inspires and encourages both students and staff to reaching their full potential. 